\title{
Developmental Changes in Eyeblink Conditioning and Neuronal Activity in the Pontine Nuclei
}

\author{
John H. Freeman Jr. ${ }^{1}$ and Adam S. Muckler \\ Department of Psychology, The University of lowa, lowa City, lowa 52242, USA
}

\begin{abstract}
Neuronal activity was recorded in the pontine nuclei of developing rats during eyeblink conditioning on postnatal days 17-18 (P17-P18) or P24-P25. A pretraining session consisted of unpaired presentations of a 300-msec tone conditioned stimulus (CS) and a 10-msec periorbital shock unconditioned stimulus (US). Five paired training sessions followed the unpaired session, consisting of 100 trials of the CS paired with the US. The rats trained on P24-P25 exhibited significantly more conditioned responses (CRs) than the rats trained on P17-P18, although both groups produced CRs by the end of training. Ontogenetic increases in pre-CS and stimulus-elicited activity in the pontine nuclei were observed during the pretraining session and after paired training. The activity of pontine units was greater on trials with CRs relative to trials without CRs in rats trained on P24-P25, but almost no CR-related modulation was observed in the pontine units of rats trained on P17-P18. The findings indicate that pontine neuronal responses to the CS and modulation of pontine activity by the cerebellum and red nucleus undergo substantial postnatal maturation. The developmental changes in pontine neuronal activity might play a significant role in the ontogeny of eyeblink conditioning.
\end{abstract}

Neurobiological studies of the ontogenetic emergence of classically conditioned responses have begun to elucidate specific developmental changes in the neural mechanisms of learning and memory (Freeman Jr. and Nicholson 2001; Nicholson and Freeman Jr. 2003). Identification of developmental mechanisms underlying the ontogeny of learning has been facilitated by the use of eyeblink conditioning as a model behavioral system (Stanton and Freeman Jr. 2000). Delay eyeblink conditioning depends on the cerebellum and interconnected brainstem structures (Thompson and Krupa 1994; Yeo and Hesslow 1998; Thompson 2000). The intermediate zone of the ipsilateral cerebellum including the interpositus nucleus and cortical lobule HVI has been shown to be necessary for acquisition and long-term retention of the conditioned eyeblink response (McCormick et al. 1982; McCormick and Thompson 1984a). Evidence supporting the necessary and sufficient role of the cerebellum in eyeblink conditioning is derived from studies that used various lesion methods, reversible inactivation, electrical stimulation, electrophysiological unit recording, and functional imaging (McCormick et al. 1982; Clark et al. 1984, 1992, 1997; McCormick and Thompson 1984a,b; Lavond et al. 1985, 1987; Yeo et al. 1985a,b; Berthier and Moore 1986, 1990; Lavond and Steinmetz 1989; Chapman et al. 1990; Steinmetz et al. 1992; Yeo and Hardiman 1992; Krupa et al. 1993; Perrett et al. 1993; Gould and Steinmetz 1994; Hesslow and Ivarsson 1994; Hardiman et al. 1996; Katz and Steinmetz 1997; Krupa and Thompson 1997; Garcia and Mauk 1998; Garcia et al. 1999; Attwell et al. 2001, 2002; Bao et al. 2002).

The necessary and sufficient pathway for the unconditioned stimulus originates in the sensory inputs to the trigeminal nuclei (Harvey et al. 1984; Schreurs 1988; van Ham and Yeo 1996). Some of the trigeminal nuclei send US-related signals to the inferior olive, which then projects to the cerebellum via climbing fibers. Climbing fibers synapse directly on neurons in the cerebellar nuclei and Purkinje cells in the cerebellar cortex (Kitai et al. 1977; van der Want et al. 1989; Sugihara et al. 2001). Stimu-

\footnotetext{
${ }^{1}$ Corresponding author.

E-MAIL john-freeman@uiowa.edu; FAX (319) 335-0191.

Article and publication are at http://www.learnmem.org/cgi/doi/10.1101/ Im.63703.
}

lation of the climbing fiber pathway can substitute for a peripheral US and can serve as a sufficient US for supporting conditioning to a tone CS (Mauk et al. 1986; Steinmetz et al. 1989). In addition, lesions or inactivation of the inferior olive prevent classical conditioning of discrete movements and impair retention (McCormick et al. 1985; Yeo et al. 1986; Voneida et al. 1990; Welsh and Harvey 1998).

The inferior olive receives an inhibitory feedback projection from the cerebellar nuclei (Andersson et al. 1988; de Zeeuw et al. 1997). Cerebellar inhibition of the inferior olive influences the rhythmic firing properties and synchrony of neuronal activity in the inferior olive (Lang et al. 1996). During eyeblink conditioning, the phasic increase in cerebellar inhibition of the inferior olive during conditioned response production can significantly inhibit olive and complex spike activity (Sears and Steinmetz 1991; Hesslow and Ivarsson 1996). The CR-related inhibition of the inferior olive virtually shuts down US-elicited complex spike activity in rabbits, but produces less complete suppression in developing rats (Sears and Steinmetz 1991; Kim et al. 1998; Nicholson and Freeman Jr. 2000, 2003). Developmental changes in cerebellar inhibition of the inferior olive were examined with neurophysiological techniques and quantitative electron microscopy, which revealed a substantial increase in the number of inhibitory synapses in the inferior olive that parallels the developmental emergence of eyeblink conditioning (Nicholson and Freeman Jr. 2003). The developmental change in cerebellar inhibition of the climbing fiber pathway indicates that the cerebellar nuclei of younger rats cannot provide inhibitory feedback to the US input pathway during and after conditioning sessions. The inhibition of climbing fiber activity during eyeblink conditioning is thought to be necessary for preventing the acquisition of redundant plasticity and for maintaining learning-specific plasticity for extended periods by keeping climbing fiber activity in a state of equilibrium after CS-US training (Kim et al. 1998; Thompson et al. 1998; Medina et al. 2002; Nicholson and Freeman Jr. 2003). The development of the US pathway is therefore in part due to the development of feedback regulation of the US input to the cerebellum. Development within the CS pathway may also play a significant role in the ontogeny of eyeblink conditioning. 
The necessary and sufficient CS pathway for a tonal stimulus originates in the initial auditory pathway and the cochlear nuclei (Steinmetz et al. 1987). The cochlear nuclei have monosynaptic projections to the pontine nuclei (Steinmetz et al. 1987; Steinmetz and Sengelaub 1992). The pontine nuclei convey CS-related stimulation to the cerebellar nuclei and the granule cells of the cerebellar cortex via mossy fibers (McCrea et al. 1977; Mihailoff 1993; Parenti et al. 2002). The axons of granule cells, the parallel fibers, synapse with Purkinje cells. The pontine projection to the interpositus nucleus is a short-latency excitatory projection (Gould et al. 1993). Electrical stimulation of the pontine nuclei or mossy fibers serves as a sufficient substitute CS for conditioning to a peripheral US (Steinmetz et al. 1985, 1986, 1989; Steinmetz 1990; Tracy et al. 1998). Moreover, the mossy fiber CS generalizes to a tone CS in some cases, indicating that the electrical stimulation CS has the same physiological effect as a tone CS. Mossy fiber stimulation has also been used as an effective CS when paired with stimulation of the climbing fiber pathway as the US (Steinmetz et al. 1989). The induction of learning with no peripheral stimuli is remarkable and demonstrates that the mossy fiber and climbing fiber pathways are the most likely pathways used during conditioning with peripheral stimuli. Moreover, there is evidence that the nature of long-term memory for eyeblink conditioning depends on potentiation of the mossy fiber inputs to the cerebellum (Tracy et al. 1998).

The cerebellum regulates the CS input pathway through an excitatory feedback connection to the pontine nuclei (Clark et al. 1997; Bao et al. 2000). The excitatory projection from the cerebellum to the pontine nuclei produces a conditioning-specific increase in activity during the production of CRs in some of the pontine neurons (McCormick et al. 1983; Clark et al. 1997; Bao et al. 2000). Cooling or pharmacological inactivation of the cerebellar interpositus nucleus prevents the expression of learning-specific activity in the pontine nuclei (Clark et al. 1997; Bao et al. 2000). In the Bao et al. (2000) study, inactivation of the interpositus nucleus abolished CRs and learning-related activity in the pontine nuclei when conditioning was produced by stimulation of the lateral reticular nucleus (LRN) as the CS. Moreover, inactivation of the pontine nuclei did not affect expression of the CR or learning-specific neuronal activity in the interpositus nucleus when lateral reticular nucleus stimulation was used as a CS. The findings of the Bao et al. study indicate that the learning-specific neuronal activity observed in the pontine nuclei during conditioning with a tone CS is produced by excitatory feedback from the cerebellum.

Previous developmental studies of eyeblink conditioning found that the activity of neurons in the cerebellar interpositus nucleus and Purkinje cells in lobule HVI of the cerebellar cortex exhibit an ontogenetic increase in the magnitude of neuronal activity during the first $100 \mathrm{msec}$ of a tone CS and CR-related activity later in the CS period (Freeman Jr. and Nicholson 2000, 2001). The present experiment examined developmental changes in neuronal activity in the pontine nuclei during eyeblink conditioning in developing rats to determine whether the developmental change in CS-elicited activity in the cerebellum is due to developmental changes in pontine responses to the CS. An additional goal of this study was to determine whether there are developmental changes in excitatory feedback from the cerebellum to the pontine nuclei, which was assessed indirectly by comparing activity on trials with CRs and trials without CRs. Developing rats were trained on postnatal days 17-18 (P17-P18) or P24-P25. The rats were first given a pretraining session that consisted of unpaired presentations of a $300-\mathrm{msec}$ tone conditioned stimulus (CS) and a 10-msec periorbital shock unconditioned stimulus (US). The pretraining session was followed by five paired training sessions. As in previous studies using these training procedures, the rats trained on P24-P25 exhibited significantly more CRs than the rats trained on P17-P18, although both groups produced CRs by the end of training (Freeman Jr. and Nicholson 2000; Nicholson and Freeman Jr. 2000, 2003). The activity profiles of neurons in the lateral pontine nuclei during pretraining revealed three general types of units: short-latency responses to CS onset, late onset responses during the CS, and short-latency responses to the CS that were sustained during the CS interval. Developmental changes in CR-related activity were assessed at the end of training, when both groups were producing CRs.

\section{RESULTS}

\section{Conditioning}

Rats trained on P24-P25 acquired CRs earlier in training than the rats trained on P17-P18 and exhibited a higher percentage of CRs by the end of training (Fig. 1). An ANOVA comparing the percentage of CRs between age groups and across sessions revealed a significant interaction of the age group and sessions factors, $F_{(4,48)}=12.16, p<0.001$. The interaction was caused by a greater percentage of CRs in the P24-P25 group relative to the P17-P18 group during sessions $3-5$ (all comparisons, $p<0.05$ ). The percentage of CRs during the pretraining session did not differ between age groups. The behavioral results replicate the findings of several previous studies that used the same behavioral training procedures and the same age comparisons (Freeman Jr. and Nicholson 2000; Nicholson and Freeman Jr. 2000, 2003).

\section{Electrode Placement}

The tips of the microwire electrodes were all within the dorsal border of the pontine nuclei. The electrodes were positioned in the medial, ventral, and lateral nuclei (Fig. 2). The positions of the electrodes were similar for the two age groups, although the electrode placements in the P24-P25 group included several slightly more medial placements relative to the electrode placements of the P17-P18 group. The electrode placements all overlapped with the areas known to project mossy fibers to the interpositus nucleus (Steinmetz and Sengelaub 1992; Tracy et al. 1998). Figure 3 displays the electrode placements by the types of unit responses recorded at each site. There was no systematic relationship between electrode placement and the types of unit responses recorded. In fact, eight (four at each age) of the electrode placements yielded units in all of the response categories. Group differences in electrode placement do not, therefore, ac-

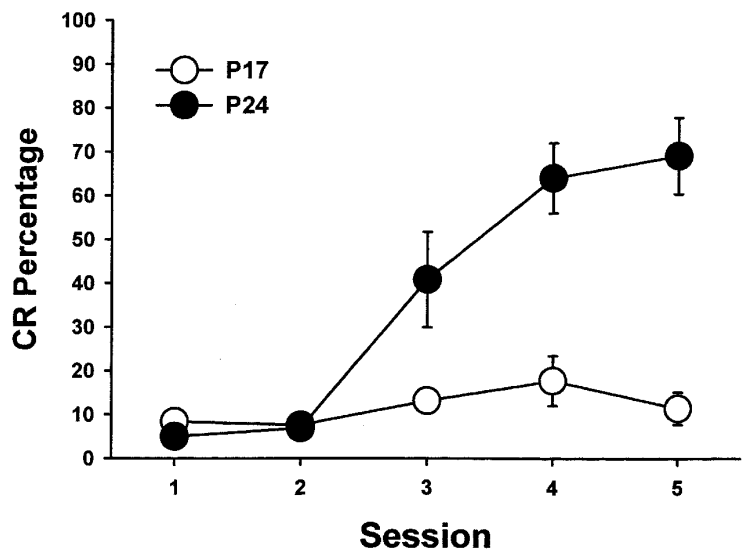

Figure 1 Mean $( \pm S E M)$ conditioned response $(C R)$ percentage from rat pups trained on postnatal days 17-18 (open circles) and postnatal days 24-25 (filled circles) across five paired training sessions. 


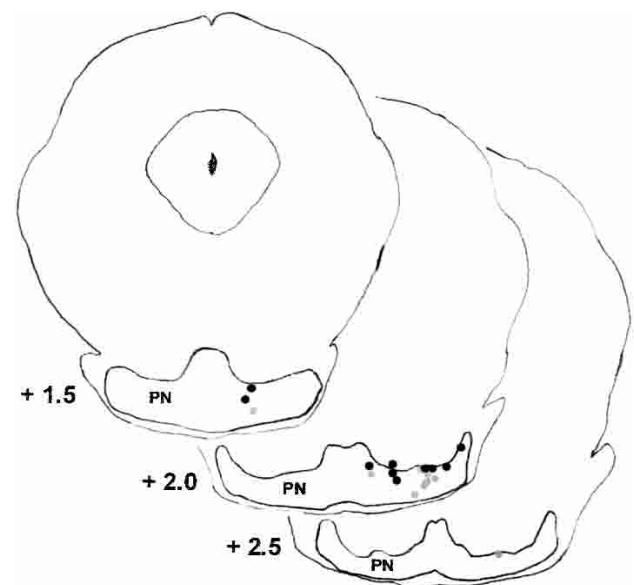

Figure 2 Drawing of three coronal sections of the infant rat brain with labels indicating the placement of the tips of the electrode bundles in the pontine nuclei (PN) for rats trained on postnatal days 17-18 (gray dots) or postnatal days 24-25 (black dots).

count for the developmental differences in unit activity described below.

\section{Unit Activity}

The unit activity recorded during pretraining presentations of the tone CS exhibited several distinct response profiles (Table 1). The phasic response units exhibited a short latency ( $<100 \mathrm{msec})$ increase in activity following the onset of the CS, which decreased to the pre-CS baseline within the second 100-msec interval (Fig. 4A). The sustained units had short latency increases in activity that were sustained for at least $200 \mathrm{msec}$ (Fig. 4B). The late units exhibited a significant increase in activity during the CS relative to the baseline, more than $100 \mathrm{msec}$ after the onset of the CS (Fig. 4C). The response characteristics of pontine units were generally consistent with a previous study, which showed phasic and sustained pontine unit profiles during acoustic stimulation in anesthetized adult cats (Aitkin and Boyd 1978).

Age-related differences were found in the percentages of neurons and in the magnitude of neuronal activity in some of the categories. The proportion of units in each category (i.e., phasic, sustained, late, and nonsignificant) did not differ significantly between age groups for the pretraining session, although there was a trend toward a higher proportion of phasic units in the P17-P18 group $(p=0.053)$. In contrast, there were significantly more sustained and late response units in the P24-P25 group relative to the P17-P18 group in the last paired training session $\left(\chi^{2}=13.36, p<0.001\right)$. There was also a smaller proportion of nonsignificant response units in the P24-P25 group relative to the P17-P18 group $\left(\chi^{2}=12.98, p<0.001\right)$, which may reflect a relatively greater recruitment of P24-P25 pontine neurons into the other unit categories as a result of conditioning. In addition, there was an increase in the proportion of sustained and late units from the pretraining session to training session 5 in the P24-P25 group, but not in the P17-P18 group. The proportion of units showing greater activity during trials with CRs relative to trials without CRs was also greater in the P24-P25 group relative to the P17-P18 group $\left(\chi^{2}=20.42, p<0.001\right.$; Fig. $5)$. The data presented in Table 1 generally indicate that there was an increase in the percentage of units showing sustained and late activity profiles that is associated with learning and production of eyeblink CRs in the P24-P25 group. In contrast, there is little change in the pattern of unit profiles following training in the P17-P18 group, even though rats in this group produced a moderate level of CRs by the fifth training session.

Analyses of age-related differences in the magnitude of pontine neuronal activity were conducted using repeated measures ANOVA. The neuronal activity in 10-msec bins was compared between groups for each neuronal response category (i.e., phasic, sustained, late response units) for the 300 -msec baseline period and the CS period, except for the last $10 \mathrm{msec}$, during which the shock US was presented on paired trials.

During the pretraining session, there was a developmental increase in pre-CS baseline activity and activity during the CS for both phasic and sustained response units (Fig. 6A,B). There was an interaction of the group and bin factors for both the phasic units, $F_{(58,3596)}=1.47, p<0.02$, and sustained units, $F_{(58,2320)}=3.32$, $p<0.001$. Post hoc tests revealed that the phasic units from the P24-P25 group exhibited greater activity than the phasic units from the P17-P18 group during pre-CS bins 3, 5, 6, 8-10, 13, 14, 17-22, 24-27, 29, and during CS bins 31, 34-49, and 51-59 (all comparisons, $p<0.05$ ). The sustained units from the P24-P25 group exhibited greater activity than the sustained units from the P17-P18 group during pre-CS bins $3,11,16,17,19,21,22,24,26$, 29,30 , and CS bins $32-50$ and 52-59 (all comparisons, $p<0.05$ ). No group differences were seen in the activity of late units or nonsignificant response units (Fig. 6C,D). The analyses of neuronal activity during paired session 5 revealed significant group differences only for the sustained units, $F_{(58,2378)}=4.00$,

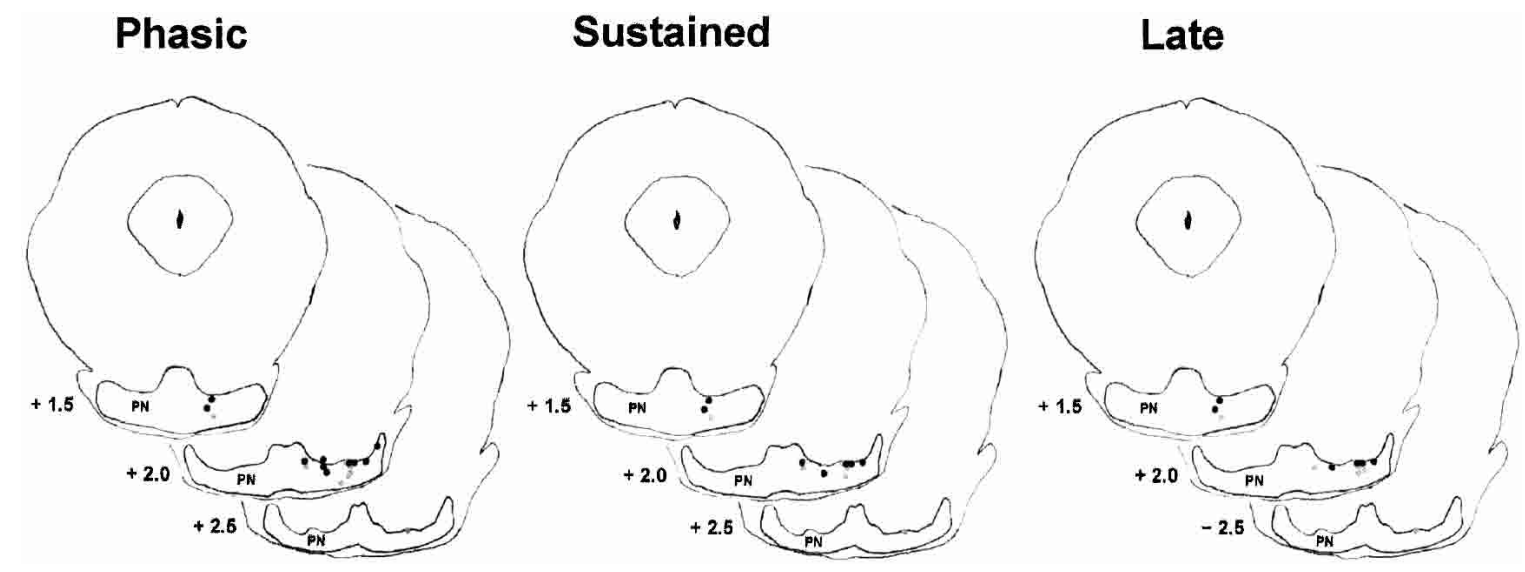

Figure 3 Drawings of three coronal sections of the infant rat brain with labels indicating the placement of the tips of the electrode bundles with phasic (left), sustained (middle), and late (right) unit response profiles (see text for definitions) in the pontine nuclei (PN) for rats trained on postnatal days 17-18 (gray dots) or postnatal days 24-25 (black dots). 
P17
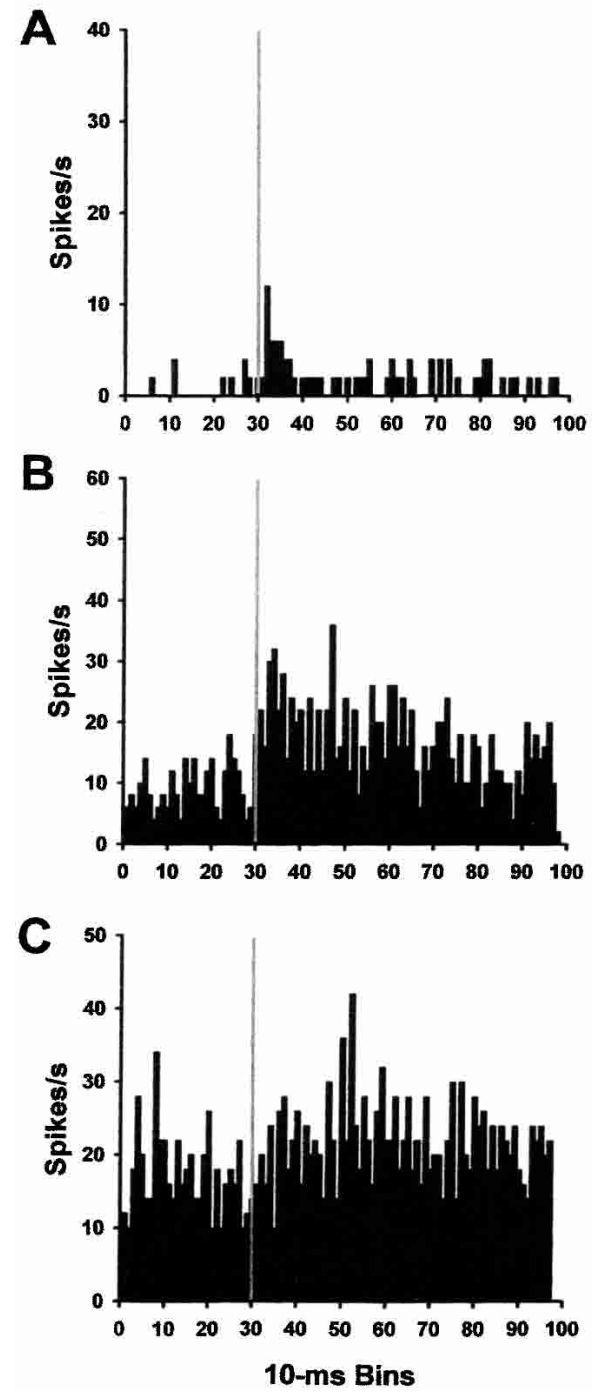

P24
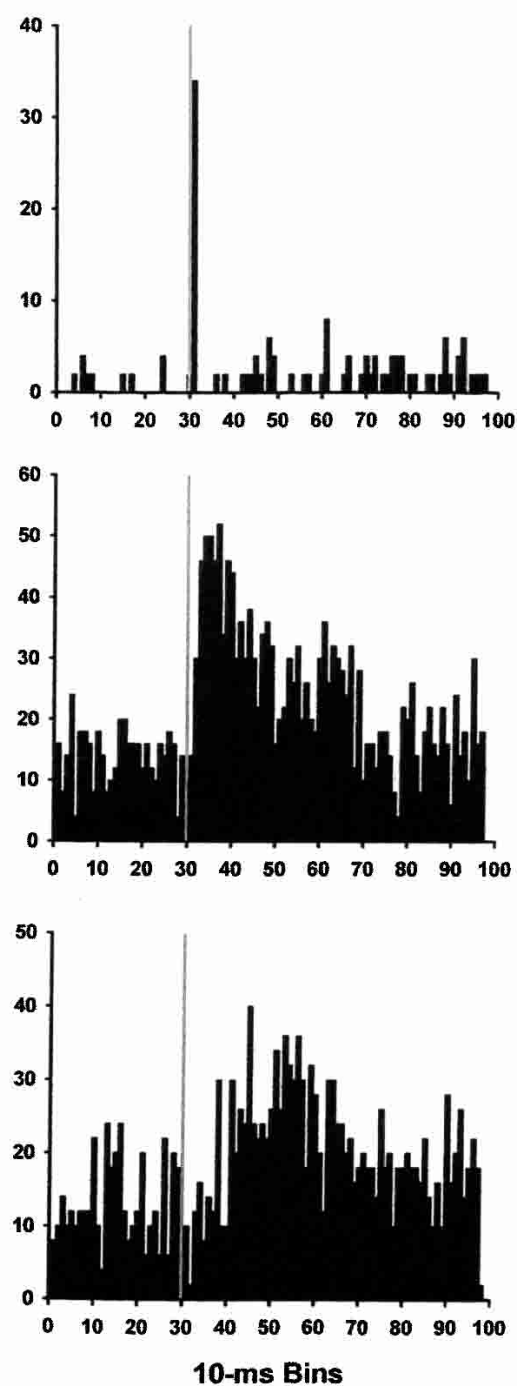

Figure 4 Mean firing rate (spikes/sec) of representative single units recorded from the pontine nuclei during the pretraining session. The firing frequencies of phasic $(A)$, sustained $(B)$, and late $(C)$ units recorded from rats trained on postnatal day 17 (P17; left column) and P24 (right column) are displayed. The gray lines indicate the onset of the conditioned stimulus.

$p<0.001$ (Fig. 7A). Post hoc comparisons revealed greater activity in the sustained units of the P24-P25 group relative to the P17P18 group during pre-CS bins 1-30 and CS bins 36-59 (all comparisons, $p<0.05$ ). The analysis of the late response units indicates that even though there was a developmental difference in the change in the number of late response units as a result of training, there was no developmental change in the magnitude of the late response unit activity (data not shown). That is, significantly more units exhibited late activity in older rats, but the activity itself was not different between the two ages. The activity of the phasic response units did not differ between groups during the pre-CS period or during the CS after paired training (Fig. 7B).

\section{DISCUSSION}

The developmental change in eyeblink conditioning between P17-P18 and P23-P24 was associated with developmental changes in stimulus-elicited and learning-related neuronal activity in the pontine nuclei. The neuronal activity profiles of units in the pontine nuclei were heterogeneous in developing rats.
Three general categories of unit activity were identified. First, there were phasic response units that exhibited a short latency $(<100 \mathrm{msec})$ increase in activity following the onset of the CS, which decreased to the pre-CS baseline within the next 100-msec interval (Fig. 4A). Second, there were sustained response units that exhibited short latency increases in activity that were sustained for at least $200 \mathrm{msec}$ (Fig. 4B). Third, there were late response units that exhibited a significant increase in activity during the CS relative to the pre-CS baseline, more than 100 msec after the onset of the CS (Fig. $4 \mathrm{C})$. An ontogenetic increase in baseline and stimulus-elicited activity was observed for the phasic and sustained response units during the pretraining session. After paired training, the rats trained on P24-P25 had significantly more sustained and late units than the rats trained on P17-P18. The baseline and stimulus-elicited activity of sustained response units was greater in the older rats after training, but the ontogenetic differences in the activity of phasic units were no longer evident after training (cf. Figs. 6A and 7B). Training also resulted in an ontogenetic increase in the number of units showing CR-related activity. Of the units recorded from the older rats during the last training session, $26 \%$ exhibited greater activity at the end of the CS on trials with CRs relative to trials without CRs (Fig. 5; Table 1). In contrast, $<6 \%$ of units recorded in the P17-P18 rats showed CR-related modulation of activity, even though these rats were producing CRs by the end of training (Fig. 1; Table 1).

Developmental changes in excitatory feedback from the cerebellum or red nucleus to the pontine nuclei could underlie the developmental change in the number of sustained and late response neurons following training. In adult rabbits, inactivation of the interpositus nucleus or the red nucleus blocks excitatory feedback to the pontine nuclei, abolishing increases in neuronal activity at the end of the CS period (Cartford et al. 1997; Clark et al. 1997; Bao et al. 2000). Excitatory feedback might be more effectively driving pontine activity during the CS in the sustained and late response units in the older rats. The basis for the putative developmental difference in excitatory feedback to the pontine nuclei could be either a developmental change in interpositus and red nuclei activity during the CS period (Freeman Jr. and Nicholson 2000) or a developmental change in the efficacy or number of synapses in the feedback projections. An analogous developmental change was recently discovered in the inhibitory feedback projection from the cerebellum to the inferior olive (Nicholson and Freeman Jr. 2000, 2003). The developmental change in the cerebellar feedback to the inferior olive is caused primarily by the addition of inhibitory synapses (Nicholson and Freeman Jr. 2003). It is possible, then, that developmental changes in pontine neuronal activity are caused by an addition of excitatory synapses within the pontine nuclei.

The age-related changes in baseline neuronal activity and phasic response unit activity during pretraining in the pontine 
Table 1. Unit Activity During Presentation of Tone CS

\begin{tabular}{|c|c|c|c|c|c|}
\hline Age & Session & Phasic & Sustained & Late & NS \\
\hline \multirow[t]{2}{*}{ P17-P18 } & UP & $29.5(43)$ & $15.8(23)$ & $5.5(8)$ & $49.3(72)$ \\
\hline & P5 & $25.6(31)$ & $8.3(10)$ & $5.8(7)$ & $60.3(73)$ \\
\hline \multirow{2}{*}{ P24-P25 } & UP & $18.9(21)$ & $17.1(19)$ & $9.9(11)$ & $54.1(60)$ \\
\hline & P5 & $17.2(22)$ & $25.8(33)^{*}$ & $19.5(25)^{*}$ & $37.5(48)^{\star}$ \\
\hline$C R>$ no $C R$ & Pre-CR (first $100 \mathrm{msec}$ ) & CR (last 200 msec) & & & \\
\hline P17-P18 & $1.9(2)$ & $5.7(6)$ & & & \\
\hline P24-P25 & $3.9(5)$ & $25.8(33)^{*}$ & & & \\
\hline
\end{tabular}

Upper part of table: Percentage and number (in parentheses) of the different types of units recorded from rats trained on postnatal days P17-18 or P24-25 during the unpaired pretraining (UP) session and the fifth paired training session (P5). Lower part of table: Percentage and number (in parentheses) of units with greater activity on trials with conditioned responses (CRs) relative to trials without CRs (CR $>$ no $C R)$ for the first 100 ms of the conditioned stimulus (Pre-CR) and the last $200 \mathrm{~ms}$ of the conditioned stimulus (CR).

*Indicates significant difference between groups, $P<0.05$.

nuclei could also be related to a developmental change in feedback from the cerebellum or red nucleus to the pontine nuclei. However, studies in adult rabbits found that cooling the cerebellum or red nucleus did not reduce baseline activity in the pontine nuclei (Cartford et al. 1997; Clark et al. 1997). It is possible that the previous studies did not record from exactly the same population of neurons examined in the present study because they selected pontine units that showed conditioning-related activity. The present study used fixed position electrodes and examined all units that could be reliably separated. Another difference between studies is that some of the baseline differences in activity in the present study were observed during pretraining, but not after training, whereas the recordings in the cited rabbit studies were made after conditioning was well established.

One of the previous studies also found that cooling the red nucleus reduced stimulus evoked activity in the pontine nuclei (Cartford et al. 1997). The developmental change in the magnitude of short latency evoked activity (phasic activity) in the pontine nuclei could therefore be related to a developmental change in the efficacy of the projection from the red nucleus to the pontine nuclei. Alternatively, projections from the cochlea to the pontine nuclei may develop between P17 and P24. An important follow-up study will be to examine the effects of interpositus nucleus and red nucleus inactivation on spontaneous and stimulus evoked neuronal activity in the pontine nuclei before training.

The heterogeneity of response profiles of pontine neurons observed in the present experiment indicates that some of the temporal specificity of CS inputs to the cerebellum might be encoded at the level of the pontine nuclei or its afferents. The combined activity of the phasic, sustained, and late response neurons might provide stimulation to the cerebellum that represents the entire CS interval. The finding of different temporal patterns of CS evoked neuronal activity in the pontine nuclei has important implications for models of cerebellar learning that posit mechanisms for encoding the temporal dynamics of the CS. In some models, much of the temporal coding of the CS occurs in the granule cell layer of the cerebellar cortex, rather than in the pontine nuclei or afferents to the pontine nuclei (Medina and Mauk 2000; Medina et al. 2000). The findings of the present study do not refute the idea that temporal encoding occurs in the granule layer, but point to the pontine nuclei as an additional source of temporal information about the CS. The presence of temporal variation in the neuronal response of pontine neurons during the CS indicates the possibility that conditioned response timing might be partially mediated by encoding different epochs during the CS through different mossy fiber inputs to the interpositus nucleus.

The developmental changes in pontine neuronal activity observed in the present study have significant implications for understanding the neural mechanisms of the ontogeny of eyeblink conditioning. The ontogenetic differences in pontine neuronal activity elicited by the tone CS indicate that the developmental difference in cerebellar responses to the CS (Freeman Jr. and Nicholson 2000; Nicholson and Freeman Jr. 2003) are at least partially caused by changes in pontine responses, rather than solely by changes in the efficacy of the mossy fiber projection to the cerebellum. However, it is possible that developmental changes in mossy fiber and parallel fiber synaptic input to cerebellar neurons play a role in the ontogeny of eyeblink conditioning. The development of CS inputs to the cerebellum could be sufficient to produce ontogenetic changes in the induction of learning-related plasticity in the cerebellum, but developmental changes in cerebellar feedback might also contribute to cerebellar plasticity, and thereby contribute to the ontogenetic emergence of eyeblink conditioning. The role of cerebellar excitatory feedback to the pontine nuclei in conditioning has not been determined. However, it has been suggested that cerebellar feedback

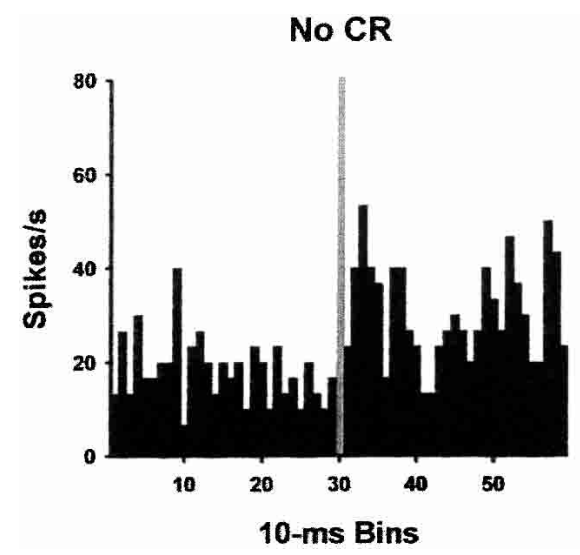

Figure 5 Mean firing rate (spikes/sec) of a pontine unit with significantly greater activity during trials with a conditioned response (CR) relative to trials with no CR. 

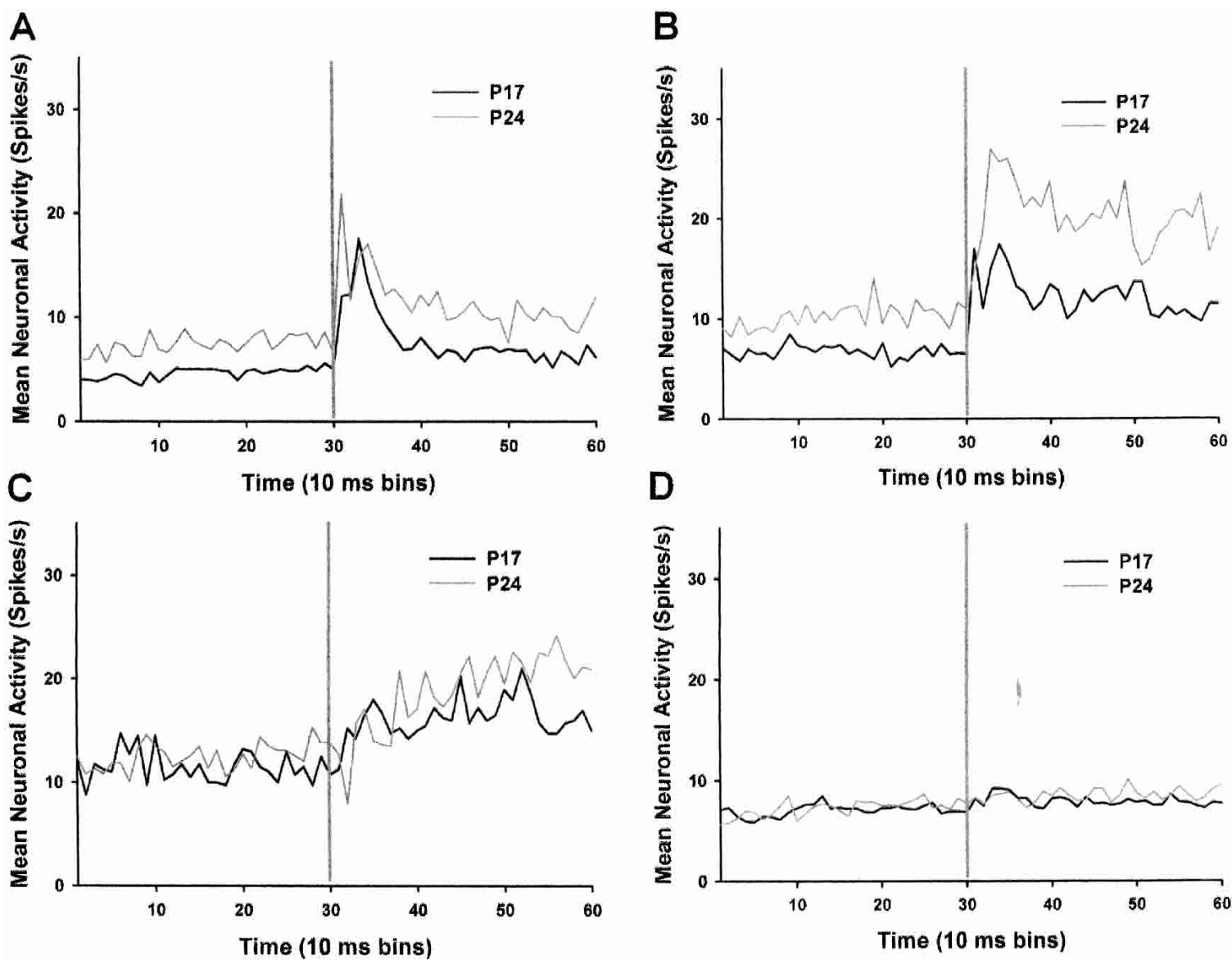

Figure 6 Mean firing rate (spikes/sec) of phasic $(A)$, sustained $(B)$, late $(C)$, and nonsignificant $(D)$ response units before and during the tone conditioned stimulus (CS). The units were recorded during the pretraining session on P17 (black line) and P24 (gray line). The vertical gray line in each graph indicates the onset of the CS.

to the pontine nuclei plays a role in enhancing CS efficacy or salience (Clark et al. 1997; Bao et al. 2000). If the enhancement of CS efficacy enhances learning, then the development of excitatory feedback from the cerebellum to the pontine nuclei could contribute to the development of eyeblink conditioning.

\section{MATERIALS AND METHODS}

\section{Subjects}

The subjects were 19 Long-Evans rat pups trained on either P17 and P18 $(n=9)$ or P24 and P25 $(n=10)$. Rats trained on P17-P18 were housed with their dams between sessions, while rats trained on P24-P25 were housed with littermates. Neuronal activity was not recorded for two of the rats trained on P24 during the pretraining session because of a temporary equipment failure. Behavioral and neuronal data were not obtained for two of the rats trained on P17 during the last training day because the dam chewed through the electrode head stage between training days. The rats were housed in the animal colony in Spence Laboratories at the University of Iowa. The rats were maintained on a 12-h light, 12-h dark photoperiod, with light onset at 7 a.m.

\section{Surgery}

The rat pups were anesthetized with an i.p. injection of ketamine hydrochloride $(100 \mathrm{mg} / \mathrm{kg})$ and xylazine $(5.0 \mathrm{mg} / \mathrm{kg})$, and given atropine $(8.0 \mathrm{mg} / \mathrm{kg})$ to reduce respiratory tract secretions and excess salivation during anesthesia. Supplements of ketamine hydrochloride $(10 \mathrm{mg} / \mathrm{mL})$ were given in $0.1-\mathrm{mL}$ increments, when needed. The rat's head was positioned in an infant stereotaxic head holder and aligned in three planes to bring it into the orientation required for placement of the electrodes. The rats were fitted with differential EMG electrodes that were implanted in the left eyelid muscle (orbicularis oculi) and a ground electrode that was attached to a stainless steel skull hook. The EMG electrode leads terminated in gold pins in a plastic connector, which was secured to the skull with dental acrylic. A bipolar stimulating electrode (for delivering the shock US) was implanted subdermally, immediately caudal to the left eye. The bipolar electrode terminated in a plastic connector that was secured to the skull by dental acrylic.

A bundle of eight insulated stainless steel microwire electrodes $(25 \mu \mathrm{m})$ was implanted in the right pontine nuclei in each rat. The stereotaxic coordinates for the pontine nuclei were taken from $\lambda(\mathrm{AP}=+1.8-2.0 \mathrm{~mm} ; \mathrm{ML}=-0.8-1.0 \mathrm{~mm}$; and $\mathrm{DV}=-8.3-$ $8.5 \mathrm{~mm}$ ). The electrode bundle was slowly lowered in increments and affixed to the skull when the neuronal activity exhibited spontaneous spikes and spikes elicited by auditory stimuli.

The electrodes were held in place by a microelectrode connector and dental acrylic applied to the skull. The surgical site was closed with sutures on both sides of the electrode plug. Lightweight cables that allowed the rats to move freely during conditioning connected the EMG electrodes, bipolar stimulating electrode, and microwire electrodes to peripheral equipment and a Pentium computer.

\section{Conditioning Apparatus}

The conditioning apparatus consisted of an electrically shielded small-animal sound attenuation chamber (BRS/LVE). Within the sound attenuation chamber was a small-animal operant chamber

\section{Learning \& Memory}


A

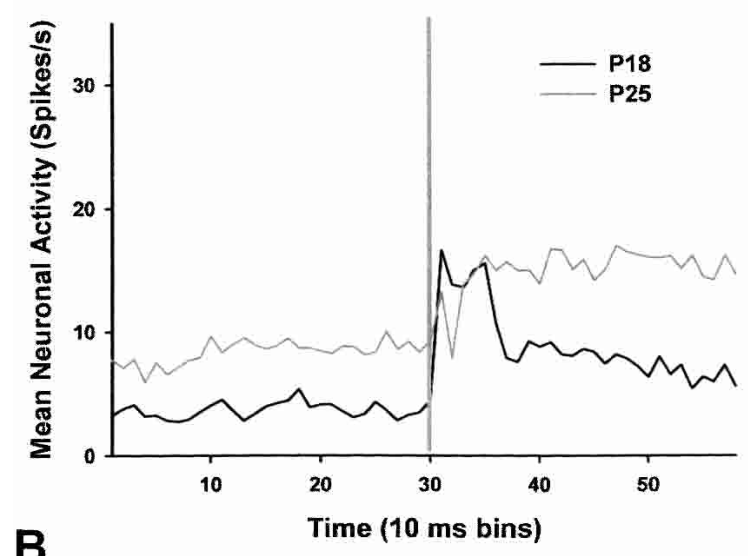

B

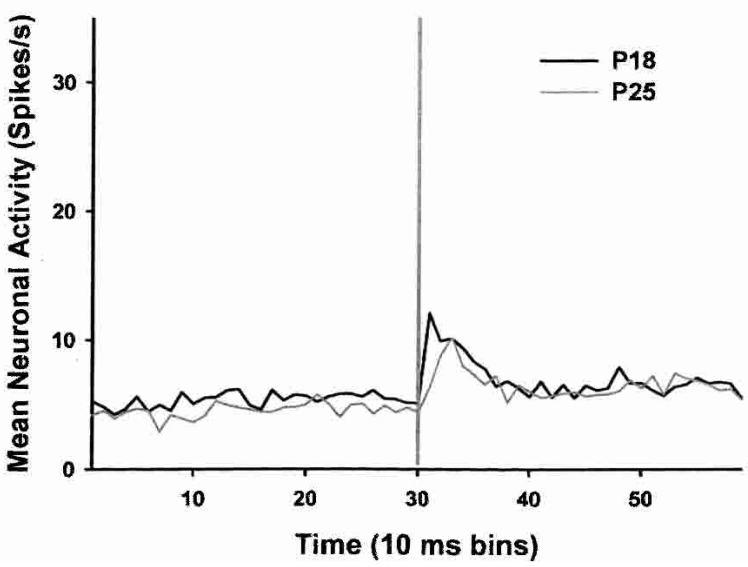

Figure 7 Mean firing rate (spikes/sec) of sustained $(A)$ and phasic $(B)$ response units before and during the tone conditioned stimulus (CS). The units were recorded during the last paired training session on P18 (black line) and P25 (gray line). The vertical gray line in each graph indicates the onset of the CS.

(BRS/LVE), where the rats were kept during conditioning. One wall of the operant chamber was fitted with two speakers. The back wall of the sound-attenuating chamber was equipped with a small house light. Computer software controlled the delivery of stimuli and the recording of eyelid EMG activity. EMG activity was recorded differentially (gain $=2000$; sampling rate $=250 \mathrm{~Hz}$ ), filtered $(500-5000 \mathrm{~Hz})$, and integrated (time constant $=20 \mathrm{msec}$ ), by equipment that was described in previous studies (Stanton et al. 1992).

\section{Conditioning Procedure}

Training sessions consisted of 100 trials each. Three sessions were run on each day of training at approximately 4-h intervals. During the first session, the rats were given explicitly unpaired presentations of a tone CS $(2.0 \mathrm{kHz}, 300 \mathrm{msec}, 85 \mathrm{~dB}$ SPL $)$ and a periorbital shock US (10 msec, $4.0 \mathrm{~mA})$ to assess developmental differences in stimulus-evoked activity without the confound of possible learning-related changes attributable to paired training. The rats were then given five training sessions, which consisted of 90 paired presentations of the tone CS and the shock US and 10 CS-alone trials. The five training sessions consisted of 10 blocks of 10 trials. Of the 10 trials in each block, there were 9 trials consisting of paired presentations of the CS and US and 1 CS-alone trial. During paired trials, the CS coterminated with the US, yielding an interstimulus interval of $290 \mathrm{msec}$.

The CS-alone trials were included to assess behavioral responses (integrated EMG activity) and neuronal activity related to the CS or CR, uncontaminated by an unconditioned response (UR; Gormezano et al. 1983).

All trials were separated by a variable intertrial interval that averaged $30 \mathrm{sec}$ (range $=18-42 \mathrm{sec}$ ). Behavioral data were examined from computer records of EMG responses. Conditioned responses (CRs) were defined as responses that crossed a threshold of 0.4 unit (amplified and integrated voltage units) above baseline during the CS period, but at least $80 \mathrm{msec}$ after CS onset, to avoid contamination of the CR measures by the startle or alpha response (Skelton 1988). Previous studies have shown that the paired training protocol used in this study established associative eyeblink CRs in developing rats (e.g., Stanton et al. 1992).

\section{Neuronal Recording Procedure}

The activity of each microwire electrode (eight for each rat) was initially passed through a unity gain JFET preamplifier (NB Labs). The outputs of the JFET preamplifier were fed into an eight-channel programmable amplifier (Lynx-8, Neuralynx), band-pass filtered between 300 and $6000 \mathrm{~Hz}$, and amplified at a gain of 10,000 . The outputs of the amplifiers were fed into a computercontrolled acquisition system at $20 \mathrm{kHz}$ per channel (Datawave Technologies, Workbench-32), where thresholding was used to detect and extract waveforms of units with signal-to-noise ratios of at least 3:1. Two voltage thresholds were used. Waveforms that crossed the lower threshold, but did not cross the upper threshold within any of the sample points, were recorded to computer disk. The waveforms were saved as separate 32-point data chunks, yielding a waveform length of $1.5 \mathrm{msec}$. The acquisition and analysis software displayed all of the waveforms that were recorded during a particular data collection period. A template matching program was used to identify all of the spikes with similar waveform characteristics. The template matching program used in this study effectively isolates single units from multiunit records (Kubota et al. 1996; Freeman Jr. and Nicholson 1999, 2000; Nicholson and Freeman Jr. 2000, 2002, 2003). Figure 8 shows digitized waveforms of two units separated from multiunit activity recorded during the last training session. The left side of the figure displays overlays of all the waveforms recorded during the 100-trial training session for two units (Fig. 8A). Individual waveforms from each of the overlays are also displayed (Fig. 8B). The consistency and stability of the unit recordings indicate that response-generated artifacts were not recorded as unit events.

\section{Data Analysis}

The behavioral data were examined for each training session. Repeated measures analysis of variance (ANOVA) was performed for the CR percentage, CR amplitude, CR latency, and UR amplitude. Significant differences were evaluated by Tukey's honestly significant difference (HSD) test (for all, $p<0.05$ ).

Peristimulus time histograms of the firing rates of each unit were created for the entire period of the conditioning trial $(1 \mathrm{sec})$ for the pretraining and the fifth paired training session. Unit

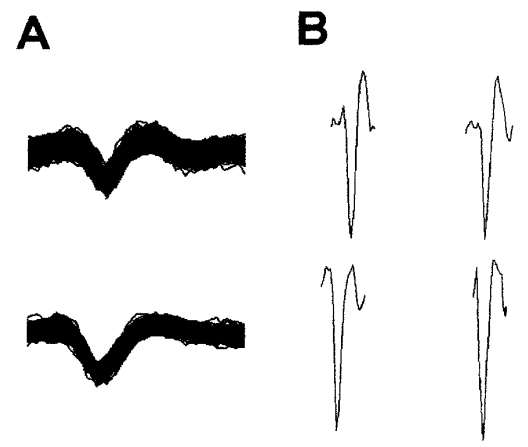

Figure 8 Overlays of all of the digitized waveforms recorded for two units during the last training session $(A)$ and individual waveforms from the overlays $(B)$. The duration of each event is $1.3 \mathrm{msec}$. 
activity from the pre-CS baseline period (300 msec) was compared with three consecutive 100-msec intervals during the CS using the Wilcoxon rank test (Kubota et al. 1996; Freeman Jr. and Nicholson 1999, 2000; Nicholson and Freeman Jr. 2000, 2002, 2003). Units were categorized into four general classes based on the results of the Wilcoxon tests. Units with activity that increased significantly above the baseline period during the first CS interval, but not the second or third intervals, were classified as phasic response units. Units with activity that increased significantly above baseline during the first CS interval and the second or third intervals were classified as sustained response units. Units with activity that increased significantly above the baseline activity during the second or third interval, but not the first interval, were classified as late response units. Units that did not show increased activity above the baseline during the CS were classified as nonsignificant response units. Analyses of paired session 5 spike data also compared CS-period activity from trials with CRs and trials without CRs. CR-related activity was not examined earlier in training because very few of the rats trained on P17-P18 exhibited CRs before session 4. The proportion of units in the different categories described above (see Table 1) was compared between age groups by Pearson $\chi^{2}$ tests.

\section{Histology}

On the day after training, the rats were killed with a lethal injection of sodium pentobarbital $(90 \mathrm{mg} / \mathrm{kg})$ and transcardially perfused with $\sim 100 \mathrm{ml}$ of physiological saline followed by $\sim 300 \mathrm{~mL}$ of $3 \%$ formalin. After perfusion, the brains were postfixed in the same fixative for a minimum of $96 \mathrm{~h}$, and subsequently sectioned at $50 \mu \mathrm{m}$ with a sliding microtome. Sections were then stained with cresyl violet. The locations of the recording electrodes were confirmed by examining serial sections.

\section{ACKNOWLEDGMENTS}

We thank Dan Nicholson for advice concerning the surgical methods and for reviewing a draft of this manuscript. This study was supported by National Institute of Neurological Disorders and Stroke grant NS38890 to JHF.

The publication costs of this article were defrayed in part by payment of page charges. This article must therefore be hereby marked "advertisement" in accordance with 18 USC section 1734 solely to indicate this fact.

\section{REFERENCES}

Aitkin, L.M. and Boyd, J. 1978. Acoustic input to the lateral pontine nuclei. Hear. Res. 1: 67-77.

Andersson, G., Garwicz, M., and Hesslow, G. 1988. Evidence for a GABA-mediated cerebellar inhibition of the inferior olive in the cat. Exp. Brain Res. 72: 450-456.

Attwell, P.J., Rahman, S., and Yeo C.H. 2001. Acquisition of eyeblink conditioning is critically dependent on normal function in cerebellar cortical lobule HVI. J. Neurosci. 21: 5715-5722.

Attwell, P.J., Cooke, S.F., and Yeo, C.H. 2002. Cerebellar function in consolidation of a motor memory. Neuron 34: 1011-1020.

Bao S., Chen, L., and Thompson, R.F. 2000. Learning- and cerebellum-dependent neuronal activity in the lateral pontine nucleus. Behav. Neurosci. 114: 254-261.

Bao, S., Chen, L., Kim, J.J., and Thompson, R.F. 2002. Cerebellar cortical inhibition and classical eyeblink conditioning. Proc. Natl. Acad. Sci. 99: 1592-1597.

Berthier, N.E. and Moore, J.W. 1986. Cerebellar Purkinje cell activity related to the classically conditioned nictitating membrane response. Exp. Brain Res. 63: 341-350.

. 1990. Activity of deep cerebellar nuclear cells during classical conditioning of nictitating membrane extension in rabbits. Exp. Brain Res. 83: 44-54.

Cartford, M.C., Gohl, E.B., Singson, M., and Lavond, D.G. 1997. The effects of reversible inactivation of the red nucleus on learning-related and auditory-evoked unit activity in the pontine nuclei of classically conditioned rabbits. Learn. Mem. 3: 519-531.

Chapman, P.F., Steinmetz, J.E., Sears, L.L., and Thompson, R.F. 1990 Effects of lidocaine injection in the interpositus nucleus and red nucleus on conditioned behavioral and neuronal responses. Brain Res. 537: 149-156.

Clark, G.A., McCormick, D.A., Lavond, D.G., and Thompson, R.F. 1984.
Effects of lesions of cerebellar nuclei on conditioned behavioral and hippocampal neuronal responses. Brain Res. 291: 125-136.

Clark, R.E., Zhang, A.A., and Lavond, D.G. 1992. Reversible lesions of the cerebellar interpositus nucleus during acquisition and retention of a classically conditioned behavior. Behav. Neurosci. 106: 879-888.

Clark, R.E., Gohl, E.B., and Lavond, D.G. 1997. The learning-related activity that develops in the pontine nuclei during classical eye-blink conditioning is dependent on the interpositus nucleus. Learn. Mem. 3: 532-544.

de Zeeuw, C.I., van Alphen, A.M., Hawkins, R.K., and Ruigrok, T.J. 1997. Climbing fiber collaterals contact neurons in the cerebellar nuclei that provide a GABAergic feedback to the inferior olive. Neuroscience 80: $981-986$.

Freeman Jr., J.H. and Nicholson, D.A. 1999. Neuronal activity in the cerebellar interpositus and lateral pontine nuclei during inhibitory classical conditioning of the eyeblink response. Brain Res. 833: $225-233$.

. 2000. Developmental changes in eye-blink conditioning and neuronal activity in the cerebellar interpositus nucleus. J. Neurosci. 20: $813-819$.

. 2001. Ontogenetic changes in the neural mechanisms of eyeblink conditioning. Integrative Physiol. Behav. Sci. 36: 15-35.

Garcia, K.S. and Mauk, M.D. 1998. Pharmacological analysis of cerebellar contributions to the timing and expression of conditioned eyelid responses. Neuropharmacology 37: 471-480.

Garcia, K.S., Steele, P.M., and Mauk, M.D. 1999. Cerebellar cortex lesions prevent acquisition of conditioned eyelid responses. $J$. Neurosci. 19: 10940-10947.

Gormezano, I., Kehoe, E.J., and Marshall, B.S. 1983. Twenty years of classical conditioning research with the rabbit. Prog. Psychobiol. Physiol. Psych. 10: 197-275.

Gould, T.J. and Steinmetz, J.E. 1994. Multiple-unit activity from rabbit cerebellar cortex and interpositus nucleus during classical discrimination/reversal eyelid conditioning. Brain Res. 652: 98-106

Gould, T.J., Sears, L.L., and Steinmetz, J.E. 1993. Possible CS and US pathways for rabbit classical eyelid conditioning: Electrophysiological evidence for projections from the pontine nuclei and inferior olive to cerebellar cortex and nuclei. Behav. Neur. Biol. 60: $172-185$.

Hardiman, M.J., Ramnani, N., and Yeo, C.H. 1996. Reversible inactivations of the cerebellum with muscimol prevent the acquisition and extinction of conditioned nictitating membrane responses in the rabbit. Exp. Brain Res. 110: $235-247$.

Harvey, J.A., Land, T., and McMaster, S.E. 1984. Anatomical study of the rabbit's corneal-VIth nerve reflex: Connections between cornea, trigeminal sensory complex, and the abducens and accessory abducens nuclei. Brain Res. 301: 307-321.

Hesslow, G. and Ivarsson, M. 1994. Suppression of cerebellar Purkinje cells during conditioned responses in ferrets. NeuroReport 5: 649-652. . 1996. Inhibition of the inferior olive during conditioned responses in the decerebrate ferret. Exp. Brain Res. 110: 36-46.

Katz, D.B. and Steinmetz, J.E. 1997. Single-unit evidence for eye-blink conditioning in cerebellar cortex is altered, but not eliminated, by interpositus nucleus lesions. Learn. Mem. 4: 88-104.

Kim, J.J., Krupa, D.J., and Thompson, R.F. 1998. Inhibitory cerebello-olivary projections and blocking effect in classical conditioning. Science 279: 570-573.

Kitai, S.T., McCrea, R.A., Preston, R.J., and Bishop, G.A. 1977. Electrophysiological and horseradish peroxidase studies of precerebellar afferents to the nucleus interpositus anterior. I. Climbing fiber system. Brain Res. 122: 197-214.

Krupa, D.J. and Thompson, R.F. 1997. Reversible inactivation of the cerebellar interpositus nucleus completely prevents acquisition of the classically conditioned eye-blink response. Learn. Mem. 3: $545-556$.

Krupa, D.J., Thompson, J.K., and Thompson, R.F. 1993. Localization of a memory trace in the mammalian brain. Science 260: 989-991.

Kubota, Y., Wolske, M., Poremba, A., Kang, E., and Gabriel, M. 1996. Stimulus-related and movement-related single-unit activity in rabbit cingulate cortex and limbic thalamus during performance of discriminative avoidance behavior. Brain Res. 721: 22-38.

Lang, E.J., Sugihara, I., and Llinas, R. 1996. GABAergic modulation of complex spike activity by the cerebellar nucleoolivary pathway in rat. J. Neurophys. 76: 255-275.

Lavond, D.G. and Steinmetz, J.E. 1989. Acquisition of classical conditioning without cerebellar cortex. Behav. Brain Res. 33: 113-164.

Lavond, D.G., Hembree, T.L., and Thompson, R.F. 1985. Effect of kainic acid lesions of the cerebellar interpositus nucleus on eyelid conditioning. Brain Res. 326: 179-182.

Lavond, D.G., Steinmetz, J.E., Yokaitis, M.H., and Thompson, R.F. 1987. Reacquisition of classical conditioning after removal of cerebellar cortex. Exp. Brain Res. 67: 569-593.

\section{Learning \& Memory}


Mauk, M.D., Steinmetz, J.E., and Thompson, R.F. 1986. Classical conditioning using stimulation of the inferior olive as the unconditioned stimulus. Proc. Natl. Acad. Sci. 83: 5349-5353.

McCormick, D.A. and Thompson, R.F. 1984a. Cerebellum: Essential involvement in the classically conditioned eyelid response. Science 223: 296-299.

. 1984b. Neuronal responses of the rabbit cerebellum during acquisition and performance of a classically conditioned nictitating membrane-eyelid response. J. Neurosci. 11: 2811-2822.

McCormick, D.A., Clark, G.A., Lavond, D.G., and Thompson, R.F. 1982. Initial localization of the memory trace for a basic form of learning. Proc. Natl. Acad. Sci. 79: 2731-2735.

McCormick, D.A., Lavond, D.G., and Thompson, R.F. 1983. Neuronal responses of the rabbit brainstem during performance of the classically conditioned nictitating membrane (NM)/eyelid response. Brain Res. 271: 73-88.

McCormick, D.A., Steinmetz, J.E., and Thompson, R.F. 1985. Lesions of the inferior olivary complex cause extinction of the classically conditioned eyeblink response. Brain Res. 359: 120-130.

McCrea, R.A., Bishop, G.A., and Kitai, S.T. 1977. Electrophysiological and horseradish peroxidase studies of precerebellar afferents to the nucleus interpositus anterior. II. Mossy fiber system. Brain Res. 122: $215-228$.

Medina, J.F. and Mauk, M.D. 2000. Computer simulation of cerebellar information processing. Nat. Neurosci. 3: 1205-1211.

Medina, J.F., Garcia, K.S., Nores, W.L., Taylor, N.M., and Mauk, M.D. 2000. Timing mechanisms in the cerebellum: Testing predictions of a large-scale computer simulation. I. Neurosci. 20: 5516-5525.

Medina, J.F., Nores, W.L., and Mauk, M.D. 2002. Inhibition of climbing fibres is a signal for the extinction of conditioned eyelid responses. Nature 416: 330-333.

Mihailoff, G.A. 1993. Cerebellar nuclear projections from the basilar pontine nuclei and nucleus reticularis tegmenti pontis as demonstrated with PHA-L tracing in the rat. J. Comparative Neurol. 330: $130-146$.

Nicholson, D.A. and Freeman Jr., J.H. 2000. Developmental changes in eye-blink conditioning and neuronal activity in the inferior olive. $J$. Neurosci. 20: 8218-8226.

. 2002. Neuronal correlates of conditioned inhibition of the eyeblink response in the anterior interpositus nucleus. Behav. Neurosci. 116: 22-36.

. 2003. Addition of inhibition in the olivocerebellar system and the ontogeny of a motor memory. Nat. Neurosci. 6: 532-537.

Parenti, R., Zappala, A., Serapide, M.F., Panto, M.R., and Cicirata, F. 2002. Projections of the basilar pontine nuclei and nucleus reticularis tegmenti pontis to the cerebellar nuclei of the rat. $J$. Comparative Neurol. 452: 115-127.

Perrett, S.P., Ruiz, B.P., and Mauk, M.D. 1993. Cerebellar cortex lesions disrupt learning-dependent timing of conditioned eyelid responses. J. Neurosci. 13: 1708-1718.

Schreurs, B.G. 1988. Stimulation of the spinal trigeminal nucleus supports classical conditioning of the rabbit's nictitating membrane response. Behav. Neurosci. 102: 163-172.

Sears, L.L. and Steinmetz, J.E. 1991. Dorsal accessory inferior olive activity diminishes during acquisition of the rabbit classically conditioned eyelid response. Brain Res. 545: 114-122.

Skelton, R.W. 1988. Bilateral cerebellar lesions disrupt conditioned eyelid responses in unrestrained rats. Behav. Neurosci. 102: 586-590.

Stanton, M.E. and Freeman Jr., J.H. 2000. Developmental studies of eyeblink conditioning in a rat model. In Eyeblink classical conditioning: Animal models (eds. D.S. Woodruff-Pak and J.E. Steinmetz), Vol. 2., pp. 105-134. Kluwer Academic Publishers, Amsterdam.

Stanton, M.E., Freeman Jr., J.H., and Skelton, R.W. 1992. Eyeblink conditioning in the developing rat. Behav. Neurosci. 106: 657-665.

Steinmetz, J.E. 1990. Neuronal activity in the rabbit interpositus nucleus during classical NM-conditioning with a pontine-nucleus-stimulation CS. Psych. Sci. 1: 378-382.

Steinmetz, J.E. and Sengelaub, D.R. 1992. Possible conditioned stimulus pathway for classical eyelid conditioning in rabbits. Behav. Neur. Biol. 57: 103-115.
Steinmetz, J.E., Lavond, D.G., and Thompson, R.F. 1985. Classical conditioning of the rabbit eyelid response with mossy fiber stimulation as the conditioned stimulus. Bull. Psychonomic Soc. 23: $245-248$.

Steinmetz, J.E., Rosen, D.J., Chapman, P.F., Lavond, D.G., and Thompson, R.F. 1986. Classical conditioning of the rabbit eyelid response with a mossy fiber stimulation CS. I. Pontine nuclei and middle cerebellar peduncle stimulation. Behav. Neurosci. 100: $878-887$

Steinmetz, J.E., Logan, C.G., Rosen, D.J., Thompson, J.K., Lavond, D.G., and Thompson, R.F. 1987. Initial localization of the acoustic conditioned stimulus projection system to the cerebellum essential for classical eyelid conditioning. Proc. Natl. Acad. Sci. 84: 3531-3535.

Steinmetz, J.E., Lavond, D.G., and Thompson, R.F. 1989. Classical conditioning in rabbits using pontine nucleus stimulation as a conditioned stimulus and inferior olive stimulation as an unconditioned stimulus. Synapse 3: 225-233.

Steinmetz, J.E., Lavond, D.G., Ivkovich, D., Logan, C.G., and Thompson, R.F. 1992. Disruption of classical eyelid conditioning after cerebellar lesions: Damage to a memory trace system or simple performance deficit? J. Neurosci. 12: 4403-4426.

Sugihara, I., Wu, H.S., and Shinoda Y. 2001. The entire trajectories of single olivocerebellar axons in the cerebellar cortex and their contribution to cerebellar compartmentalization. J. Neurosci. 21: $7715-7723$.

Thompson, R.F. 2000. Discovering the brain substrates of eyeblink classical conditioning. In Eyeblink classical conditioning: Animal models (eds. D.S. Woodruff-Pak and J.E. Steinmetz), Vol. 2., pp. 17-49. Kluwer Academic Publishers, Amsterdam.

Thompson, R.F. and Krupa, D.J. 1994. Organization of memory traces in the mammalian brain. Ann. Rev. Neurosci. 17: 519-549.

Thompson, R.F., Thompson, J.K., Kim, J.J., Krupa, D.J., and Shinkman, P.G. 1998. The nature of reinforcement in cerebellar learning. Neurobiol. Learn. Mem. 70: 150-176.

Tracy, J.A., Thompson, J.K., Krupa, D.J., and Thompson, R.F. 1998. Evidence of plasticity in the pontocerebellar conditioned stimulus pathway during classical conditioning of the eyeblink response in the rabbit. Behav. Neurosci. 112: 267-285.

van der Want, J.J.L., Wiklund, L., Guegan, M., Ruigrok, T., and Voogd, J. 1989. Anterograde tracing of the rat olivocerebellar system with Phaseolus vulgaris leucoagglutinin (PHA-L). Demonstration of climbing fiber collateral innervation of the cerebellar nuclei. $J$. Comparative Neurol. 288: 1-18.

van Ham, J.J. and Yeo, C.H. 1996. The central distribution of primary afferents from the external eyelids, conjunctiva, and cornea in the rabbit, studied using WGA-HRP and B-HRP as transganglionic tracers. Exp. Neurol. 142: 217-225.

Voneida, T.J., Christie, D., Bogdanski, R., and Chopko, B. 1990. Changes in instrumentally and classically conditioned limb-flexion responses following inferior olivary lesions and olivocerebellar tractotomy in the cat. J. Neurosci. 10: 3583-3593.

Welsh, J.P. and Harvey, J.A. 1998. Acute inactivation of the inferior olive blocks associative learning. Eur. $I$. Neurosci. 10: 3321-3332.

Yeo, C.H. and Hardiman, M.J. 1992. Cerebellar cortex and eyeblink conditioning: A reexamination. Exp. Brain Res. 88: 623-638.

Yeo, C.H. and Hesslow, G. 1998. Cerebellum and conditioned reflexes. Trends Cog. Sci. 2: 322-330.

Yeo, C.H., Hardiman, M.J., and Glickstein, M. 1985a. Classical conditioning of the nictitating membrane response of the rabbit. I. Lesions of the cerebellar nuclei. Exp. Brain Res. 60: 87-98.

. 1985b. Classical conditioning of the nictitating membrane response of the rabbit. II. Lesions of the cerebellar cortex. Exp. Brain Res. 60: 99-113.

. 1986. Classical conditioning of the nictitating membrane response of the rabbit. IV. Lesions of the inferior olive. Exp. Brain Res. 63: 81-92.

Received May 30, 2003; accepted in revised form July 16, 2003. 


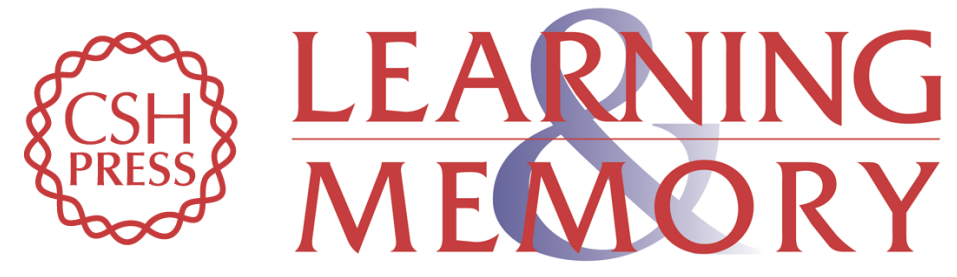

\section{Developmental Changes in Eyeblink Conditioning and Neuronal Activity in the Pontine Nuclei}

John H. Freeman, Jr. and Adam S. Muckler

Learn. Mem. 2003, 10:

Access the most recent version at doi:10.1101/lm.63703

References This article cites 74 articles, 20 of which can be accessed free at: http://learnmem.cshlp.org/content/10/5/337.full.html\#ref-list-1

License

Email Alerting Receive free email alerts when new articles cite this article - sign up in the box at the Service top right corner of the article or click here. 